\title{
Parâmetros dendrométricos e excentricidade da medula em árvores inclinadas de eucalipto
}

\author{
Dendrometric parameters and eccentricity \\ of the pith in leaning eucalypt trees
}

\author{
Walter Torezani Neto Boschetti ${ }^{1}$, Juarez Benigno Paes ${ }^{2}$, Graziela Baptista Vidaurre ${ }^{2}$, \\ Marina Donária Chaves Arantes ${ }^{2}$ e Fernando Palha Leite ${ }^{3}$
}

\begin{abstract}
Resumo
O objetivo deste estudo foi analisar os parâmetros dendrométricos e a presença da madeira de reação pela assimetria da medula em árvores Eucalyptus grandis $x$ Eucalyptus urophylla destinados à produção $\mathrm{e}$ celulose, inclinadas por ação de ventos. As medições em altura foram feitas com relascópio eletrônico; as mensurações de diâmetro por meio da equação de Smalian; a excentricidade foi ajustada entre o centro geométrico e a medula. Foi encontrado menor comprimento comercial de fuste e menor diâmetro a 1,30 metros do solo (DAP) nas árvores inclinadas. O ângulo de inclinação do tronco nas árvores não influenciou na relação cerne:alburno e no teor de madeira e de casca dentro de uma mesma árvore, porém houve uma perda de volume de madeira e casca. Conforme a inclinação do tronco aumentou, ocorreu uma tendência de incremento na excentricidade da medula nas árvores e, consequentemente uma maior incidência em madeira de reação.
\end{abstract}

Palavras-chave: Produtividade, assimetria da medula, qualidade da madeira.

\begin{abstract}
The aim of this study was to analyze the dendrometric parameters and occurrence the reaction wood by asymmetry of the pith in the tree of Eucalyptus grandis $x$ Eucalyptus urophylla destined to pulp production, leaning due to wind action. The height measurements were made with electronic relaskop, the diameter measurements by Smalian equation; the eccentricity was set between the geometric center and the core. A lower commercial length of stem and a smaller diameter at $1.30 \mathrm{~m}$ above the ground $(\mathrm{DBH})$ of the inclined trees was found. The inclination angle in the trees did not affect the core relationship: heartwood:sapwood and wood and bark content within the same tree; however, there was a loss of wood volume and bark. As the inclination of the trunk increases, there is a trend of increase in the eccentricity of the pith and therefore a greater increase in reaction wood in the trees.
\end{abstract}

Keywords: Productivity, asymmetry of the pith, wood quality.

\section{INTRODUÇÃO}

A demanda da indústria de celulose por madeira proveniente de espécies florestais de rápido crescimento, como a do gênero Eucalyptus, é o principal instigador para o desempenho crescente do setor florestal brasileiro. No entanto, árvores jovens com fuste muito alto, apresentam maior instabilidade, especialmente à ação de ventos.

A ação dos ventos é um fator natural e impossível de ser controlada. Esta ocorrência em plantios comerciais pode trazer estresse às árvores, e afetar na produtividade e na qualidade da madeira. Quando ocorre de forma acentuada, pode causar danos de forma irreversível. A quebra do tronco e a derrubada da árvore pela raiz são danos que ocasionam a sua morte. Já em fustes inclinados, a árvore permanece viva, realizando fotossíntese e produzindo madeira.

\footnotetext{
${ }^{1}$ Doutorando do Programa de Pós-Graduação em Ciência Florestal. UFV - Universidade Federal de Viçosa - 36570-000 Viçosa, MG. E-mail: walterboschetti@hotmail.com

2Professor (a) Doutor (a) do Departamento de Ciências Florestais e da Madeira. UFES - Universidade Federal do Espírito Santo. Caixa Postal 16 - 29550-000 - Jerônimo Monteiro, ES. E-mail: ibp2@uol.com.br, grazividaurre@gmail.com, mdonariac@hotmail.com.

3Pesquisador Doutor da Celulose Nipo-Brasileira S.A. CENIBRA - Caixa Postal 100 - 35.196-000 - Belo Oriente, MG. E-mail: fernando.leite@cenibra.com.br
} 
Problemas com ventos em plantios florestais já foram relatados por Sousa (2004); Ferreira et al. (2010); Rosado et al. (2013); Braz et al. (2014) em plantios florestais de eucalipto na região do Vale do Rio Doce em Minas Gerais, onde tempestades ocasionaram prejuízos provocados por rajadas de ventos, que geralmente ocorrem nos períodos de chuva entre os meses de outubro a março.

Após a ocorrência do evento, o incremento de madeira nas árvores inclinadas ocorre de forma anormal, denominado como madeira de reação. Em espécies de folhosas, este lenho é designado como madeira de tração e oposta, que pode afetar a sua qualidade, sendo o principal indício a excentricidade da medula (CLAIR; THIBAULT, 2001; WASHUSEN; EVANS, 2001; RUELLE et al., 2006; AGUAYO et al., 2010). Todavia, a inclinação do fuste pode contribuir também com a modificação das características dendrométricas das árvores, influenciando na quantificação do volume, no conteúdo de madeira e de casca e nas relações cerne:alburno.

Estudar as características dendrométricas das árvores inclinadas por ação de ventos é fundamental para detectar o potencial de produtividade dos plantios afetados. Além disso, analisando-se a excentricidade da medula é possível estimar a variação potencial da qualidade da madeira produzida.

Dentro desse contexto, o objetivo deste estudo foi analisar os parâmetros dendrométricos e a presença da madeira de reação pela assimetria da medula em árvores de Eucalyptus grandis $x$ Eucalyptus urophylla inclinadas por ação de ventos, destinadas à produção de celulose.

\section{MATERIAL E MÉTODOS}

A madeira utilizada neste estudo foi proveniente de plantio florestal clonal comercial do híbrido Eucalyptus grandis $\mathrm{x}$ Eucalyptus urophylla, proveniente do município de Ipaba, localizado na região do Vale do Rio Doce, leste do Estado de Minas Gerais. A Região localiza-se a $19^{\circ} 23^{\prime} 45^{\prime \prime}$ de Latitude Sul e $42^{\circ} 23^{\prime} 40^{\prime \prime}$ de Longitude Oeste.

As árvores foram plantadas em fevereiro de 2007 em terreno de baixada, com espaçamento de $3,00 \mathrm{~m} \times 3,33 \mathrm{~m}$. O talhão foi atingido pela ação de ventos com velocidade de até $72 \mathrm{~km} \mathrm{~h}^{-1}, 33$ meses após o plantio. O corte ocorreu em janeiro de 2013, 38 meses após a ocorrência dos ventos no talhão.

\section{Caracterização da amostragem}

Grande parte das árvores do talhão foi inclinada pela ação de ventos, no entanto, as árvores apresentavam diferentes graus de inclinação. Desta forma, as árvores foram selecionadas ao acaso e separadas por faixas de acordo com o ângulo de inclinação.

Foram utilizadas quatro faixas de inclinação conforme a Figura 1. Na faixa 1, ou controle, as árvores praticamente não apresentavam inclinação. Nas faixas de inclinação 2, 3 e 4, as árvores foram ajustadas e classificadas em ângulos de $15^{\circ}$.

\section{Determinação do ângulo de inclinação das árvores}

A altura comercial das árvores foi considerada até o diâmetro mínimo de $6,0 \mathrm{~cm}$. Neste ponto, foram medidas a coordenada altura (Y) por meio do aparelho relascópio eletrônico, e a variação do tronco em relação ao solo $(\mathrm{X})$ por medições com trena (Figura 2).

O ângulo de inclinação das árvores $\left(\Theta^{\circ}\right)$ em relação ao eixo vertical foi ajustado pela Equação 1. Desta forma, pode-se ter um parâmetro da flecha formada pela inclinação, da base até a altura comercial, possibilitando a homogeneização da amostragem.

$$
\operatorname{Arctg} \Theta^{o}=(X / Y) \quad(1)
$$

em que: $\mathrm{X}$ é o deslocamento do tronco inclinado em relação ao solo (m); Y é a altura comercial vertical da árvore inclinada $(\mathrm{m})$. 


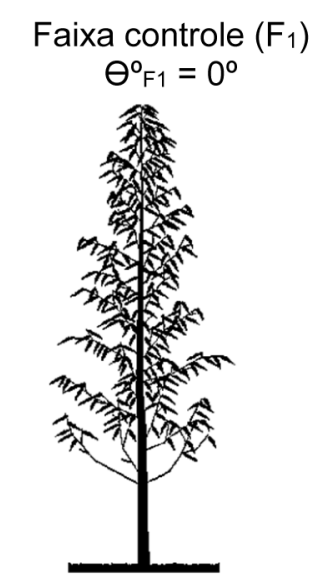

Faixa $2\left(F_{2}\right)$

$5^{\circ}<\theta^{\circ} \mathrm{F} 2 \leq 20^{\circ}$

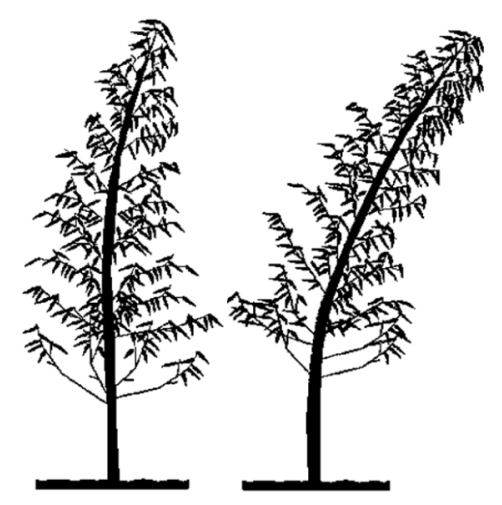

Faixa $3\left(\mathrm{~F}_{3}\right)$

$20^{\circ}<\theta^{\circ}{ }_{\mathrm{F} 3} \leq 35^{\circ}$

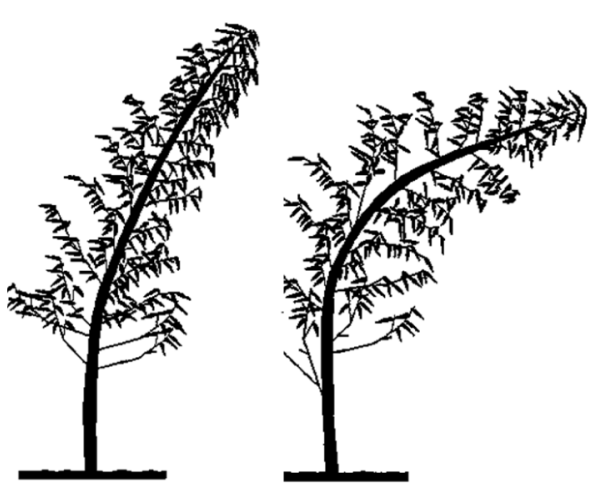

Faixa $4\left(\mathrm{~F}_{4}\right)$

$35^{\circ}<\theta^{\circ} \mathrm{F} 4 \leq 50^{\circ}$

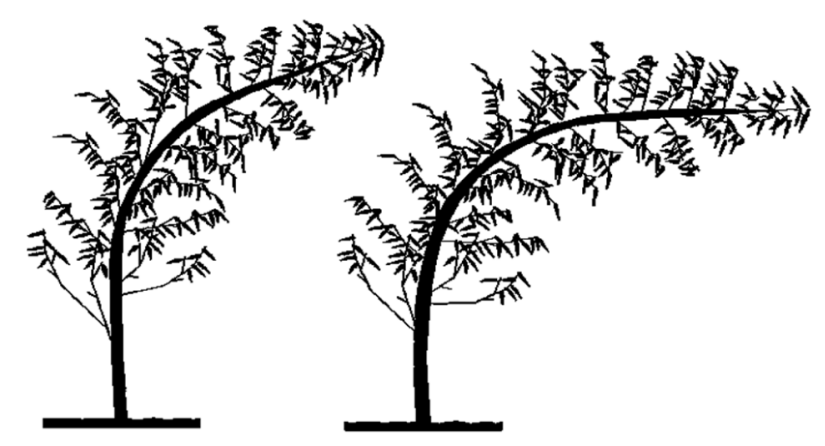

Figura 1. Faixas de inclinação das árvores. Figure 1. Inclination bands of trees.

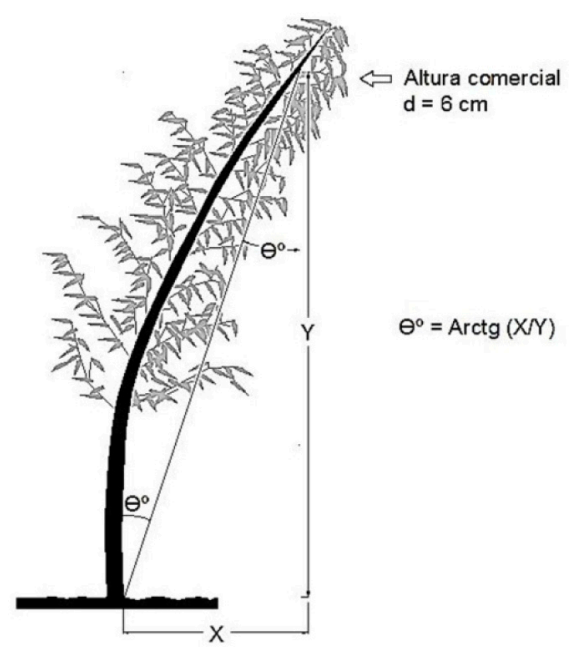

Figura 2. Metodologia de determinação do ângulo de inclinação. Figure 2. Methodology of determination of the inclination angle.

\section{Obtenção dos parâmetros dendrométricos e da excentricidade da medula}

$\mathrm{O}$ índice de esbeltez foi obtido pela relação entre a altura total da árvore e o diâmetro a 1,30 $\mathrm{m}$ do solo (DAP). É conveniente ressaltar que o índice de esbeltez foi calculado somente para as árvores não inclinadas com os dados obtidos no período em que as mesmas foram coletadas. As árvores inclinadas não foram consideras esbeltas, pois a altura do fuste $(\mathrm{Y})$ não correspondia ao seu comprimento comercial. 
Todas as árvores foram seccionadas nas posições 0, 25, 50, 75 e 100\% do comprimento comercial do tronco, e obtido o volume de madeira e volume de casca pelo método de Smalian, a relação cerne:alburno pela mensuração do diâmetro médio do cerne e do alburno, com o uso de uma régua graduada em milímetros.

A excentricidade da medula foi ajustada pela Equação 2. Foram obtidos os raios de cada disco nas posições 0, 25, 50, 75 e 100\% do comprimento comercial do tronco, pela utilização de duas marcações ao longo da extensão diametral, ao coincidir pela medula. As variáveis da distância entre o centro geométrico e a medula $\left(\mathrm{L}_{\mathrm{c}}\right)$ foram obtidas pelo procedimento proposto por Lima et al. (2007).

$$
\mathrm{EXM}=\frac{\mathrm{L}_{\mathrm{c}}}{\mathrm{d}_{\mathrm{m}}} \times 100
$$

em que: EXM é a excentricidade da medula (\%); $\mathrm{L}_{c}$ é a distância entre o centro geométrico e a medula $(\mathrm{cm}) ; \mathrm{d}_{\mathrm{m}}$ é diâmetro médio do disco $(\mathrm{cm})$.

\section{Análise estatística}

Os dados dos parâmetros dendrométricos foram analisados considerando-se os tratamentos dispostos em um delineamento inteiramente casualizado, com cinco repetições. Para os dados da excentricidade da medula foi adotado um delineamento inteiramente casualizado, considerando os tratamentos dispostos no esquema de parcelas subdivididas com cinco repetições, sendo as parcelas (faixa de inclinação) e as subparcelas (posição do tronco).

Os tratamentos dos parâmetros dendométricos e, os dados das parcelas foram avaliados estatisticamente por meio de análise de variância adotando-se um nível de significância de até 5\% de probabilidade. Quando estabelecidas diferenças significativas, a comparação entre os diferentes tratamentos foi feita pelo teste de Tukey a 5\% de significância. Os dados das subparcelas (posições do comprimento do tronco) foram avaliados por análise de regressão.

\section{RESULTADOS E DISCUSSÃO}

\section{Caracterização dendrométrica das árvores}

Os parâmetros dendrométricos das árvores foram afetados pelas diferentes faixas de inclinação do tronco, conforme a Tabela 1. Algumas características das árvores com o tronco reto foram significativamente maiores que as faixas das árvores inclinadas. Observou-se maior média de valores de comprimento comercial e total de fuste nas árvores da faixa controle.

Após a ocorrência dos danos provocados pelos ventos, as árvores inclinadas perderam a dominância apical, cessando o crescimento em altura, refletindo em menor comprimento de fuste quando comparado às árvores de tronco reto que continuaram a crescer em altura. As árvores inclinadas ficaram com a copa a uma altura mais baixa que as não inclinadas, crescendo em condições desfavoráveis com competição por luz. Nessas condições, as árvores são induzidas a recuperar a dominância apical a partir de brotos no fuste, para tentar promover uma nova copa (SOUSA, 2004). Estas condições de competição por luz resultam em estresse nas árvores inclinadas e, acarretaram em um menor incremento em diâmetro das mesmas (MITSUDA et al., 2002).

Os valores do comprimento comercial do fuste e do DAP das árvores não inclinadas, estão próximos aos encontrados por Santos (2011) em árvores do mesmo híbrido e mesma idade, porém plantados em sítios diferentes. Por outro lado, os valores do DAP das árvores não inclinadas são superiores e, os valores de comprimento comercial do fuste estão dentro dos valores encontrados por Barbosa (2013), em árvores do mesmo híbrido, com a mesma idade, plantados na mesma região. Isto indica que o crescimento e incremento em madeira das árvores com o fuste reto não foram prejudicados ou favorecidos, em decorrência da inclinação de árvores do mesmo talhão.

Observa-se que as médias do comprimento comercial do tronco para as árvores inclinadas não diferiram. Desta forma, a altura das árvores em relação ao eixo vertical (Y) foi inversamente proporcional com a inclinação da árvore, consolidando a eficiência da metodologia do ângulo de inclinação das árvores em relação ao eixo vertical. 
Tabela 1. Valores médios dos parâmetros dendrométricos em árvores de clone de Eucalyptus grandis $\mathrm{x}$ Eucalyptus urophylla em diferentes faixas de inclinação, aos seis anos de idade.

Table 1. Mean values of the dendrometric parameters in trees of clones of Eucalyptus grandis $\mathrm{x}$ Eucalyptus urophylla in different inclination bands, at six years of age.

\begin{tabular}{|c|c|c|c|c|}
\hline \multirow{2}{*}{ Parâmetros Dendométricos } & \multicolumn{4}{|c|}{ Faixa de Inclinação do Fuste } \\
\hline & F1 & F2 & F3 & F4 \\
\hline Comprimento total do fuste $(\mathrm{m})$ & $\begin{array}{c}29,2 \mathrm{a} \\
(2,9)\end{array}$ & $\begin{array}{c}20,4 \mathrm{~b} \\
(2,3)\end{array}$ & $\begin{array}{c}20,7 \mathrm{~b} \\
(1,0)\end{array}$ & $\begin{array}{c}19,6 \mathrm{~b} \\
(1,1)\end{array}$ \\
\hline Comprimento comercial do fuste (m) & $\begin{array}{l}24 \mathrm{a} \\
(3,6)\end{array}$ & $\begin{array}{c}16,7 \mathrm{~b} \\
(1,2)\end{array}$ & $\begin{array}{l}17 \mathrm{~b} \\
(0,8)\end{array}$ & $\begin{array}{c}15,1 \mathrm{~b} \\
(1,4)\end{array}$ \\
\hline Altura $Y(m)$ & $\begin{array}{c}29,2 \mathrm{a} \\
(2,9)\end{array}$ & $\begin{array}{c}17,6 \mathrm{~b} \\
(1,9)\end{array}$ & $\begin{array}{c}12,9 \mathrm{c} \\
(1,4)\end{array}$ & $\begin{array}{l}9,5 \mathrm{c} \\
(1,3)\end{array}$ \\
\hline $\mathrm{DAP}(\mathrm{cm})$ & $\begin{array}{c}21,45 a \\
(3,93)\end{array}$ & $\begin{array}{c}16,17 \mathrm{~b} \\
(0,66)\end{array}$ & $\begin{array}{c}17,57 \mathrm{ab} \\
(1,51)\end{array}$ & $\begin{array}{c}16,01 \mathrm{~b} \\
(1,57)\end{array}$ \\
\hline Volume de madeira sem casca $\left(\mathrm{m}^{3}\right)$ & $\begin{array}{c}0,433 a \\
(0,15)\end{array}$ & $\begin{array}{c}0,183 \mathrm{~b} \\
(0,01)\end{array}$ & $\begin{array}{c}0,219 \mathrm{~b} \\
(0,05)\end{array}$ & $\begin{array}{c}0,151 \mathrm{~b} \\
(0,03)\end{array}$ \\
\hline Volume de casca $\left(\mathrm{m}^{3}\right)$ & $\begin{array}{c}0,068 \text { a } \\
(0,02)\end{array}$ & $\begin{array}{c}0,032 \mathrm{~b} \\
(0,01)\end{array}$ & $\begin{array}{c}0,032 \text { b } \\
(0,01)\end{array}$ & $\begin{array}{c}0,024 \mathrm{~b} \\
(0,01)\end{array}$ \\
\hline Teor de madeira (\%) & $86,5 \%$ & $84,5 \%$ & $87,3 \%$ & $85,8 \%$ \\
\hline Teor de casca $(\%)$ & $13,5 \%$ & $15,1 \%$ & $12,7 \%$ & $14,2 \%$ \\
\hline Teor de alburno (\%) & $\begin{array}{l}58,4 \\
(6,4)\end{array}$ & $\begin{array}{l}59,7 \\
(2,5)\end{array}$ & $\begin{array}{l}61,6 \\
(4,3)\end{array}$ & $\begin{array}{l}60,2 \\
(2,1)\end{array}$ \\
\hline Relação cerne:alburno & $\begin{array}{l}0.728 \\
(0,18)\end{array}$ & $\begin{array}{l}0.676 \\
(0,07)\end{array}$ & $\begin{array}{l}0.627 \\
(0,11)\end{array}$ & $\begin{array}{l}0.662 \\
(0,06)\end{array}$ \\
\hline Índice de esbeltez & 1,38 & -- & -- & --- \\
\hline
\end{tabular}

Médias seguidas pelas mesmas letras não diferem estatisticamente pelo teste de Tukey $(p>0,05)$. Os valores entre parêntesis é o desvio padrão.

As árvores inclinadas, em decorrência do menor comprimento de fuste e menor incremento de madeira em diâmetro, tiveram uma queda de 57,5\% no volume de madeira e de 56,8\% no volume de casca, comparado ao volume de madeira e casca das árvores não inclinadas (Figura 3).

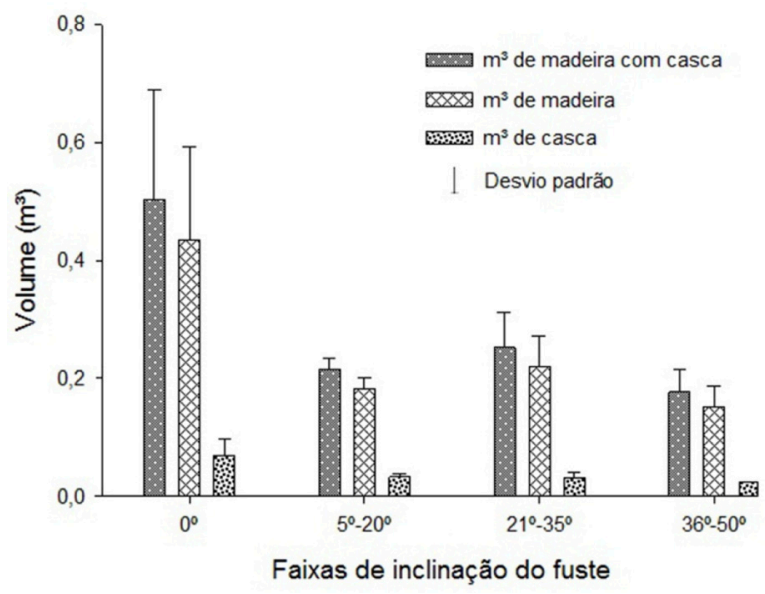

Figura 3. Volume médio de madeira e casca em árvores de clone de Eucalyptus grandis x Eucalyptus urophylla, em diferentes faixas de inclinação, aos seis anos de idade.

Figure 3. Mean volumes of wood and bark in trees of clones of Eucalyptus grandis $\mathrm{x}$ Eucalyptus urophylla in different inclination bands, at six years of age.

É possível observar na Figura 3 o efeito negativo na produção de madeira em decorrência da inclinação dos troncos pela ação dos ventos. O ritmo de produção das indústrias de celulose é influenciado pela quantidade de matéria-prima que a empresa tem disponível. Desta forma, a quantidade de matéria-prima merece atenção nas perspectivas de produção e expansão dessas indústrias, para que matéria-prima não falte ou se torne mais onerosa. Assim, dependendo da quantidade de plantios afetados em uma mesma empresa, deve-se ter o cuidado de não superestimar os valores de madeira nos plantios que tiveram danos por ação de ventos. 
Em geral, o fuste de uma árvore acusou ter 15\% de casca e 85\% de madeira. Apesar do menor volume de madeira e casca, as árvores inclinadas apresentaram a mesma proporção de madeira e casca que as árvores da faixa controle. Isto indica que independente da faixa de inclinação do tronco, as árvores não irão produzir mais madeira que casca, ou vice-versa (Tabela 1).

O nível de inclinação do fuste, em ocorrência dos ventos, não influenciou na relação de cerne e alburno no tronco $(0,65$, aproximadamente). Na Figura 4, observa-se a maior proporção de alburno que cerne nas quatro faixas de inclinação. Maior proporção de alburno contribui positivamente para a produção de celulose, pois cavacos oriundos do alburno têm maior permeabilidade, sendo facilmente impregnados pelos reagentes no digestor, facilitando a polpação (FOELKEL, 2009). A menor proporção de cerne nas árvores estudadas é justificada por serem árvores jovens. Ferreira et al., (1979) explica que o envelhecimento das árvores promove transformações na madeira, tal como aumento na proporção do cerne.

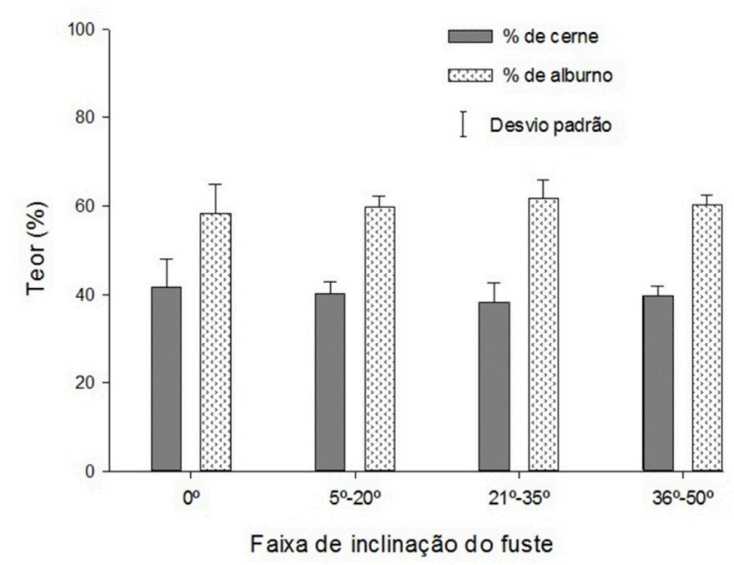

Figura 4. Teor de cerne e alburno em árvores de clone de Eucalyptus grandis x Eucalyptus urophylla, em diferentes faixas de inclinação, aos seis anos de idade.

Figure 4. Heartwood and sapwood content in trees of clones of Eucalyptus grandis $x$ Eucalyptus urophylla, in different inclination bands, at age six years.

Em árvores do mesmo híbrido, com mesma idade, plantado na mesma região, os teores de madeira e de casca, e o teor de alburno estão próximos aos valores encontrados por São Teago (2012), $86,7 \%$ de madeira, 13,3\% de casca e, 60,14\% de alburno respectivamente. Já Barbosa (2013) encontrou valor superior no teor de madeira, 92,8\%; e consequentemente menor valor no teor de casca, $7,2 \%$.

O índice de esbeltez calculado para o hibrido estudado, nas árvores com inclinação nula foi superior a 1. Este resultado significa que com o aumento da altura das árvores, a cada metro, incrementou menos que $1,0 \mathrm{~cm}$ em DAP, tornando-as menos robustas e mais instáveis a ventos (DURLO; DENARDI, 1998). O alto índice de esbeltez pode ser explicado pelo fato de que o incremento em diâmetro não acompanha o crescimento em altura, ou seja, a atividade do tecido meristemático apical é muito mais intensa que a atividade do tecido meristemático na região cambial nos primeiros anos de vida das árvores, pois em plantios comerciais, as árvores são induzidas a crescer primeiro em altura em decorrência do espaçamento e da competição por luz.

É conveniente ressaltar que a média do índice de esbeltez para as árvores não inclinadas foi ajustada com os dados obtidos no período em que as mesmas foram colhidas. Acredita-se que, na idade em que as mesmas foram inclinadas, próximo aos três anos, que foi o período crítico em que tiveram maior grau de esbeltez, tornando-as mais instáveis e suscetíveis a ação de ventos.

\section{Excentricidade da medula}

Nos fustes inclinados, as seções transversais foram quase todas excêntricas na forma. O maior raio encontra-se na parte de cima da inclinação, ou seja, no lado tracionado; na parte inferior a inclinação do tronco, o crescimento foi suprimido. Na Tabela 2, nota-se um aumento significativo da excentricidade da medula conforme aumentou a inclinação dos fustes. 
As árvores da faixa controle tiveram medula excêntrica, porém com menor intensidade que as árvores com o fuste inclinado. Ferreira et al. (2008), também notaram medula excêntrica em árvores com fuste reto em clones de Eucalyptus grandis $\times$ Eucalyptus urophylla e Eucalyptus grandis aos sete anos de idade. A média dos valores da excentricidade da medula das árvores para a faixa controle foi de 4,11\%. Ferreira et al. (2004), ao estudarem dez clones com idades de 7 a 10 anos, encontraram excentricidade média da medula de 5,6\%.

Tabela 2. Valores médios de excentricidade nas quatro faixas de inclinação e, o comportamento o longo do tronco, em árvores de clone de Eucalyptus grandis x Eucalyptus urophylla, aos seis anos de idade.

Table 2. Mean values of eccentricity in the four inclination bands and behavior along the trunk in trees of clones of Eucalyptus grandis x Eucalyptus urophylla, at age six years.

\begin{tabular}{lcccc}
\hline & \multicolumn{5}{c}{ Faixa de Inclinação do Fuste } \\
\hline Posição do Tronco & F1 & F2 & F3 & F4 \\
\hline \multirow{2}{*}{$0 \%$} & 4,99 & 1,06 & 6,92 & 8,61 \\
& $(1,4)$ & $(1,5)$ & $(6,4)$ & $(3,8)$ \\
\hline \multirow{2}{*}{$25 \%$} & 3,17 & 6,28 & 10,67 & 9,18 \\
& $(2,6)$ & $(2,5)$ & $(4,5)$ & $(3,6)$ \\
\hline \multirow{2}{*}{$50 \%$} & 2,68 & 6,97 & 6,95 & 5,42 \\
& $(0,7)$ & $(5,0)$ & $(3,1)$ & $(2,3)$ \\
\hline \multirow{2}{*}{$75 \%$} & 3,02 & 5,15 & 6,2 & 6,82 \\
& $(2,2)$ & $(4,0)$ & $(4,0)$ & $(3,7)$ \\
\hline \multirow{2}{*}{$100 \%$} & 4,09 & 5,32 & 7,3 & 10,2 \\
& $(0,9)$ & $(4,2)$ & $(5,1)$ & $(6,2)$ \\
\hline \multirow{2}{*}{ Excentricidade da medula (\%) } & $3,60 \mathrm{~b}$ & 6,14 ab & 7,61 a & 8,04 a \\
\end{tabular}

Médias seguidas pelas mesmas letras não diferem estatisticamente pelo teste de Tukey $(p>0,05)$. Os valores entre parêntesis é o desvio padrão.

Não houve interação significativa entre as médias das faixas de inclinação e posição do tronco e, não houve um modelo ajustado que caracterizasse um perfil de variação de excentricidade da medula no sentido longitudinal. É importante advertir que todos os parâmetros avaliados possuíram alto valor de desvio padrão. Maiores valores de excentricidade da medula foram encontrados nas posições mais próximas a base e ao topo do fuste (Tabela 2).

Valores altos de excentricidade são um forte indicativo em incremento de madeira de tração (KOLLMANN; CÔTÉ JÚNIOR, 1968; DLOUHÁ et al., 2008; WANG et al., 2010). Nas posições com maior excentricidade da medula e, em decorrência da assimetria biomecânica no tronco das árvores inclinadas, possivelmente há um maior incremento em madeira de tração.

Toras com valores altos de excentricidade de medula são mais propensas à formação de fendas circulares (GROSSER, 1980). Esta desvantagem é considerada para produção de madeira serrada e para produção de cavacos, pois dependendo da umidade da tora para a transformação em cavacos, as fendas podem aumentar a quantidade de cavacos finos, que serão descartados no processo de polpação nas peneiras, afetando a produtividade decavacos dentro dafábrica. Além disto, a madeira dereaçãoaumentaa variabilidade do lenho e, influencia na qualidade da madeira e nos parâmetros para produção de polpa. Por esse motivo é necessário realizar estudos mais aprofundados sobre as características do lenho das árvores inclinadas.

\section{CONCLUSÕES}

As árvores inclinadas pelos ventos tiveram diminuição do comprimento comercial de fuste e do diâmetro, acarretando em um menor volume de madeira e de casca quando comparadas às árvores com fuste reto.

A proporção entre madeira e casca e a relação entre cerne e alburno não foram influenciadas pelas inclinações dos troncos.

Quanto maior a inclinação do tronco maior a excentricidade da medula encontrada e, não foi encontrado relação entre excentricidade da medula e posição do tronco no sentido longitudinal para as árvores do clone estudado. 
Boschetti et al. - Parâmetros dendrométricos e excentricidade da medula em árvores inclinadas de eucalipto

Levando-se em consideração a qualidade da madeira, a excentricidade da medula reflete em maior incidência de madeira de tração de acordo com o aumento da inclinação do tronco, que poderá refletir na qualidade da madeira formada e, consequentemente, nos parâmetros de polpação.

\section{REFERÊNCIAS BIBLIOGRÁFICAS}

AGUAYO, M. G.; QUINTUPILL, L.; CASTILLO, R.; BAEZA, J.; FREER, J.; MENDONÇA, R. T. Determination of differences in anatomical and chemical characteristics of tension and opposite wood of 8-year old Eucalyptus globulus. Maderas: Ciencia y Tecnologia, Concepción, v. 12, n. 3, p. 241-251, 2010.

BARBOSA, T. L. Qualidade da madeira de clones de Eucalyptus grandis $x$ Eucalyptus urophylla cultivados em cinco regiões do Estado de Minas Gerais para produção de celulose. 2013. 126 p. Dissertação (Mestrado em Ciências Florestais) - Universidade Federal do Espírito Santo, Jerônimo Monteiro, 2013.

BRAZ, E. L.; OLIVEIRA, J. T. O.; ROSADO, A. M.; VIDAURRE, G. B. V.; PAES, J. B. Parâmetros dendrométricos e resistência mecânica das árvores de clones de Eucalyptus em áreas sujeitas à ação dos ventos. Ciência Florestal, Santa Maria, v. 24, n. 4, p. 947-958, 2014.

CLAIR, B.; THIBAULT, B. Shrinkage of the gelatinous layer of poplar and beech tension wood. IAWA Journal, Leiden, v. 22, n. 2, p. 121-131, 2001.

DLOUHÁ, J.; ALMÉRAS, T.; CLAIR, B.; GRIL, J.; HORACEK, P. Biomechanical performances of trees in the phase of active reorientation. Acta Universitatis Agriculturae et Silviculturae Mendelianae Brunensis, Czech Republic, v. 56, n. 5, p. 39-45, 2008.

DURLO, M. A.; DENARDI, L. Morfometria de Cabraela canjerana, em mata secundária nativa do Rio Grande do Sul. Ciência Florestal, Santa Maria, v. 8, n. 1, p. 55-66, 1998.

FERREIRA, C. A.; FREITAS, M.; FERREIRA, M. Densidade básica da madeira de plantações comerciais de eucaliptos, na região de Mogi-Guaçu (SP). IPEF, Piracicaba, n. 18, p. 106-117, 1979.

FERREIRA, S.; LIMA, J. T.; ROSADO, S. C. S.; TRUGILHO, P. F. Influência de métodos de desdobro tangenciais no rendimento e na qualidade da madeira de clones de Eucalyptus spp. Cerne, Lavras, v. 10, n. 1, p. 10-21, 2004.

FERREIRA, S.; LIMA, J. T.; TRUGILHO, P. F.; MONTEIRO, T. C. Excentricidade da medula em caules de clones de Eucalyptus cultivados em diferentes topografias. Cerne, Lavras, v. 14, n. 4, p. 335-340, 2008.

FERREIRA, S.; LIMA, J. T.; TRUGUILHO, P. F.; SILVA, J. R. M. S.; ROSADO, A. M.; MONTEIRO, T. C. Resistência mecânica de caules de clones de Eucalyptus cultivados em diferentes topografias. Cerne, Lavras, v. 16, Supl., p. 133-140, 2010.

FOELKEL, C. E. B. O processo de impregnação dos cavacos de madeira de eucalipto pelo licor Kraft de cozimento. In: Eucalyptus Online Book \& Newsletter. Porto Alegre: Celsius Degree, 2009. 97 p. Disponível em: < http://engmadeira.yolasite.com/resources/Impregnacao\%20de\%20cavacos.pdf >. Acesso em: 05 jan. 2015

GROSSER, D. Defeitos de madeira. Curitiba: Fupef, 1980. 62 p. (Série Técnica, 2).

KOLLMANN, F. F. P.; CÔTÉ JÚNIOR., W. A. Principles of wood science and technology. New York: SpringerVerlag, 1968. v. 1, 592 p. 
LIMA, I. L.; GARCIA, J. N.; STAPE, J. L. Influência do desbaste e da fertilização no deslocamento da medula e rachaduras de extremidade de tora de Eucalyptus grandis Hill ex-Maiden. Cerne, Lavras, v. 13, n. 2, p. 170-177, 2007.

MITSUDA, Y.; ITO, S.; TAKATAET, K. Effects of competitive and cooperative interaction among neighboring trees on tree growth in a naturally regenerated even-aged Larix sibirica Stand in considering height stratification. Journal of Forest Research, Tokyo, v. 7, p. 185-191, 2002.

ROSADO, A. M.; ATAÍDE, G. M.; CASTRO, R. V. O.; CORREIA, A. C. G. Avaliação da tolerância à quebra por vento em árvores de eucalipto via teste de resistência. Pesquisa Florestal Brasileira, Colombo, v. 33, n. 75, p. 309-315, 2013.

RUELLE, J.; CLAIR, B.; BEAUCHENE, J.; FOURNIER, M. Tension wood and opposite wood in 21 tropical rain forest species 2. Comparison of some anatomical and ultrastructural criteria. IAWA Journal, Leiden, v. 27, n. 4, p. 341-376, 2006.

SANTOS, M. D. Efeito do espaçamento de plantio na biomassa do fuste de um clone híbrido interespecífico de Eucalyptus grandis e Eucalyptus urophylla. 2011. 152 p. Dissertação (Mestrado em Ciências Florestais) Universidade Estadual Paulista "Júlio de Mesquita Filho", Botucatu, 2011.

SÃO TEAGO, G. B. Qualidade das madeiras de acácia e eucalipto provenientes de cultivo misto visando a produção de celulose. 2012. 111 p. Dissertação (Mestrado em Ciências Florestais) - Universidade Federal do Espírito Santo. Jerônimo Monteiro, 2012.

SOUSA, L. C. Caracterização da madeira de tração em Eucalyptus grandis e sua influência na produção de polpa celulósica. 2004. 93 p. Dissertação (Mestrado em Ciência Florestal), Universidade Federal de Viçosa, Viçosa, 2004.

WANG, Y.; GRIL, J.; CLAIR, B.; MINATO, K.; SUGIYAMA, J. Wood properties and chemical composition of the eccentric growth branch of Viburnum odoratissimum var. awabuki. Trees, New York, v. 24, n. 3, p. 541-549, 2010.

WASHUSEN, R.; EVANS, R. The association between cellulose crystallite width and tension wood occurrence in Eucalyptus globulus. IAWA Jounal, Leiden, v. 22, n. 3, p. 235-243, 2001.

Recebido em 18/08/2014

Aceito para publicação em 20/05/2015 
